\title{
Adiponectin, chemerin, cytokines, and dipeptidyl peptidase 4 are released from human adipose tissue in a depot-dependent manner: an in vitro system including human serum albumin
}

Henrik Svensson ${ }^{1}$, Birgitta Odén', Staffan Edén ${ }^{2}$ and Malin Lönn ${ }^{1,3^{*}}$

\begin{abstract}
Background: Adipose tissue (AT) contributes to metabolic dysfunction through imbalanced production of adipokines, including cytokines. Visceral AT in particular is associated with metabolic disorders, indicating a specific secretory status. The relative significance of different human AT depots in adipokine release is not fully known. Further, previous in vitro systems usually included medium containing bovine serum albumin (BSA), which may induce cytokine release. Our aim was to compare release of a number of adipokines/cytokines - all implicated in insulin resistance - from human subcutaneous and visceral AT in a short-term incubation system minimizing cytokine induction and including repeated measurements during $24 \mathrm{~h}$. A prerequisite was to evaluate a potential alternative to BSA in the incubation medium.
\end{abstract}

Methods: Subcutaneous and/or visceral AT from 17 patients (age 20-68 years; BMl 22.6-56.7 kg/m²) undergoing elective surgery was incubated for $2,4,6,8$, and $24 \mathrm{~h}$ in medium with or without $1 \% \mathrm{BSA}$ or human serum albumin (HSA). Medium concentrations of adiponectin, chemerin, nine cytokines, dipeptidyl peptidase 4 (DPP4), and omentin were analyzed by multiplex immunoassay or ELISA. Adipocyte size, AT macrophage density, and medium concentrations of endotoxin were determined.

Results: Cytokine release was induced by BSA but not by HSA. In evaluation of the final incubation protocol including 1\% HSA, and as expected, adiponectin release was higher from subcutaneous biopsies of nonobese than of obese subjects and inversely associated with adipocyte size; omentin was released almost exclusively from visceral AT. Exploratory incubations revealed more abundant release of chemerin, cytokines (except IL-6), and DPP4 from the visceral depot, while adiponectin release was higher from subcutaneous than visceral AT. Release was linear for a maximum of 2-6 h. Macrophage density was higher in visceral than subcutaneous AT. Levels of endotoxin in the medium were negligible.

Conclusions: Adiponectin, chemerin, many cytokines, and DPP4 are released from human AT in a depotdependent manner. These results highlight functional differences between visceral and subcutaneous AT, and a mechanistic link between regional fat accumulation and metabolic disorders. Supplementation of human AT incubation medium with HSA rather than BSA is recommended to minimize induction of cytokine release.

Keywords: Adipokines, Cytokines, Subcutaneous adipose tissue, Visceral adipose tissue, Metabolic disease, Insulin resistance, Inflammation, Bovine serum albumin, Human serum albumin

\footnotetext{
* Correspondence: malin.lonn@medic.gu.se

${ }^{3}$ Department of Clinical Chemistry, Sahlgrenska University Hospital, Bruna stråket 16, S-413 45 Gothenburg, Sweden

Full list of author information is available at the end of the article
} 


\section{Background}

Adipose tissue is a major signaling organ that produces and releases many proteins with autocrine, paracrine, and endocrine activity, the so-called adipokines [1,2]. Dysregulated secretion of adipokines, caused by obesity and/or adipose tissue dysfunction, may contribute to the pathogenesis of metabolic disease, such as insulin resistance, type 2 diabetes, and cardiovascular disease [3]. Much attention has focused on adipokines with pro-inflammatory or anti-inflammatory activities since there is evidence of a connection between obesity, its co-morbidities, and signs of chronic low-grade inflammation $[4,5]$.

Accumulation of visceral fat in particular is strongly associated with metabolic disorders [6,7], indicating that this depot may have a specific secretory status. Differences in cellular composition, adipocyte size, or other intrinsic factors could account for the regional specificity in adipokine release $[8,9]$. However, the relative significance of human subcutaneous and visceral adipose tissue in adipokine release has not been fully elucidated. Interestingly, gene expression studies revealed that expression of molecules involved in inflammation is higher in visceral adipose tissue [10-12]. However, differences in specific mRNA expression levels may not always be reflected in corresponding differences at the level of protein release. Short-term incubation of tissue pieces and subsequent analysis of the medium has been used to determine which proteins are actually released from adipose tissue depots and to what extent. Various systems for this purpose have been described that differ in supplementation of the medium, incubation time, proportion of tissue to medium, and other factors that may affect the outcome [13-17]. Thus, the challenge using an incubation strategy is to obtain results that reflect the in vivo situation [18].

Addition of bovine serum albumin (BSA) to the medium is often recommended in protocols for adipose tissue incubation, since albumin binds fatty acids that are mobilized and exert toxic effects when unbound [19]. In 2006 it was reported that BSA markedly induces production and release of cytokines from isolated human adipocytes [20]. This suggests that a BSA alternative not inducing cytokine release would be optimal, for example when comparing adipokine/cytokine release from specific adipose tissue depots [18]. Human serum albumin (HSA) has previously been used for supplementation of medium for both short-term and long-term incubation of human adipose tissue [16,21]. However, the influence of BSA versus HSA on cytokine release from human adipose tissue in vitro has not been assessed.

In this study, our aim was to compare the release of adipokines, including cytokines and other inflammatory/ metabolic biomarkers, from human subcutaneous and visceral adipose tissue in a short-term incubation system minimizing induction of cytokine release, and including repeated measurements during $24 \mathrm{~h}$. Further, a prerequisite was to first evaluate the influence of different albumin preparations regarding induction of cytokine release from human AT. Using our final incubation protocol, we investigated nine pro-inflammatory cytokines, the anti-inflammatory and intensively studied adiponectin, and chemerin and dipeptidyl peptidase 4 (DPP4), all with incompletely investigated, controversial or unexplored depot-dependent release.

\section{Methods \\ Subjects}

Adipose tissue biopsies were obtained from 17 patients (6 men and 11 women) undergoing elective abdominal surgery (abdominoplasty in 5, gall bladder removal in 2, hysterectomy in 1, and Roux-en-Y gastric bypass (RYGB) in 9). The mean age was $48.7 \pm 13.1 \mathrm{yr}$ (range 20-68 yr), and the mean BMI was $35.8 \pm 10.8 \mathrm{~kg} / \mathrm{m}^{2}$ (range $22.6-$ $56.7 \mathrm{~kg} / \mathrm{m}^{2}$ ). Subcutaneous abdominal adipose tissue biopsies were obtained from all subjects. Paired biopsies of subcutaneous and visceral (omentum) adipose tissue were collected from the 11 subjects (5 men and 6 women) undergoing gall bladder surgery or RYGB; these subjects had a mean age of $52.2 \pm 15.1 \mathrm{yr}$ (range 20-68 yr) and a mean BMI of $41.6 \pm 8.9 \mathrm{~kg} / \mathrm{m}^{2}$ (range $27.0-56.7 \mathrm{~kg} / \mathrm{m}^{2}$ ). No subjects with malignant disease were included. All participants gave oral and written consent. The study was conducted in accordance with the Declaration of Helsinki and approved by the Regional Ethical Review Board, University of Gothenburg.

\section{Short-term incubation}

Biopsies were initially handled as described in our protocol for long-term incubation [21,22]. In brief, pieces of adipose tissue (5-15 mg) were prepared under sterile conditions and incubated in plastic tubes $(250 \mathrm{mg}$ of tissue/10 $\mathrm{mL}$ of medium). In our final short-term incubation protocol, the tissue explants were incubated for 2 , $4,6,8$, and $24 \mathrm{~h}$ (one incubation tube for each incubation period) in Medium 199 (Invitrogen, Carlsbad, CA) supplemented with $30 \mathrm{mM} \mathrm{NaHCO}, 0.15 \mu \mathrm{M}$ adenosine, 1\% HSA (Baxter Medical AB, Kista, Sweden), $0.1 \mathrm{mg} / \mathrm{mL}$ cephalotin (Eli Lilly, Indianapolis, IN), $\mathrm{pH}$ adjusted to 7.4. Medium was then removed and centrifuged for $5 \mathrm{~min}$ at $450 \mathrm{~g}$. Aliquots of medium were stored at $-80^{\circ} \mathrm{C}$ until analysis.

To evaluate the influence of albumin preparation, exploratory incubations for $2,4,6,8$, and 24 h were carried out in medium lacking albumin and in medium supplemented with 1\% HSA, 1\% BSA Fraction V, or 1\% BSA Essentially Fatty Acid Free (Sigma-Aldrich, St Louis, MO).

The influence of $0.1 \%$ BSA was also studied. For practical reasons, only one tube of tissue was incubated with 
each medium, which was replaced after $4 \mathrm{~h}$. After additional $20 \mathrm{~h}$ incubation, the second portion of incubation medium was removed.

All incubations were performed at $37^{\circ} \mathrm{C}$ in a $5 \% \mathrm{CO}_{2}$ atmosphere in an incubator (Steri-cycle $\mathrm{CO}_{2}$ Incubator, Thermo Fischer Scientific, Marietta, $\mathrm{OH}$ ); the medium was stirred gently with a rotator.

\section{Adipokine release}

A multiplex immunoassay was used to measure the levels of nine cytokines in the incubation medium: granulocytemacrophage colony-stimulating factor (GM-CSF), interferon$\gamma$ (IFN- $\gamma)$, IL-1 $\beta$, IL-2, IL-6, IL-8, IL-10, IL-12p70, and TNF- $\alpha$ (Human Pro-Inflammatory 9-Plex Ultra-Sensitive Kit, Meso Scale Discovery, Gaithersburg, MD). ELISA was used to measure adiponectin (Human adiponectin ELISA kit, Millipore, Billerica, MA), chemerin (Human chemerin ELISA kit, Millipore), omentin (Human omentin-1 ELISA, Millipore), IL-6 (Quantikine High Sensitivity Human IL-6 ELISA, R\&D Systems, Minneapolis, MN), and DPP4 (Quantikine Human DPPIV/CD26 ELISA kit, R\&D Systems). Adipokine concentrations were expressed per g adipose tissue.

\section{Adipocyte size}

About $500 \mathrm{mg}$ of each fresh biopsy was digested with collagenase [23], and the mean adipocyte diameter was determined by computerized image analysis [24] with Leica software (Leica QWin V3; Leica Microsystems, Wetzlar, Germany). The cell suspension was placed between a siliconized glass slide and a cover slip and transferred to the microscope (X5 objective, DM6000B, Leica Microsystems). Twelve random visual fields were photographed with a CCD-camera (DFC320, Leica Microsystems). Uniform microspheres, $98 \mu \mathrm{m}$ in diameter (Dynal, Invitrogen Corporation, Oslo, Norway), served as reference. Mean adipocyte volume was calculated with the Goldrick formula [25].

\section{Immunohistochemistry}

Paired subcutaneous and visceral adipose tissue specimens were fixed in phosphate-buffered formalin, dehydrated, embedded in paraffin and sectioned at $4 \mu \mathrm{m}$. After hydration and heat-induced antigen retrieval, a monoclonal antibody targeted at human CD68 was added to detect macrophages (Anti-Human CD68 clone PG-M1, DakoCytomation, Denmark). MACH 3 Mouse AP-Polymer and Warp Red was used as secondary and detection reagents (Biocare Medical Concord, CA). The sections were counter stained with hematoxylin and mounted. Slides were digitalized (Mirax Desk Digital Slide Scanner, Zeiss, Göttingen, Germany) and macrophages were counted and normalized for analyzed section area (Mirax Viewer, Zeiss). Origin of the tissue was unknown to the observer.

\section{Endotoxin in incubation media}

The endotoxin concentrations in unconditioned medium with or without $1 \%$ of the different albumin preparations were analyzed at the Laboratory of Clinical Bacteriology, Sahlgrenska University Hospital, using a LAL assay with quantitative chromogenic end point (Limulus Amebocyte Lysate Endosafe Endochrome-K, Charles River Endosafe, Charleston, SC). The lower limit of detection was $0.5 \mathrm{pg} / \mathrm{mL}$. All determinations were performed at least in duplicate.

\section{Statistical analysis}

Values are expressed as mean \pm SEM. To stabilize variances, values were logarithm-transformed. The influence of different albumin preparations (1\%) on adipokine release over time was determined by three-way analysis of variance (medium, time, subject) followed by paired $t$ test and Bonferroni correction. The influence of $0.1 \%$ BSA was evaluated by two-way analysis of variance (medium, subject) followed by Dunnett's test. Differences in adipokine release from subcutaneous and visceral adipose tissue over time were assessed by threeway analysis of variance (depot, time, subject). To assess differences in adiponectin release between obese and nonobese subjects, we designed a split-plot experiment with subjects as main plots and times as subplots. Differences between groups were estimated from main plots, and differences between times were estimated from subplots [26]. Adipocyte size and macrophage density in subcutaneous and visceral adipose tissue was compared by paired $t$ test. The relationship between adiponectin release and adipocyte size was investigated with Pearson correlation analysis. Simple regression was used to investigate the relationship between IL- 6 concentrations in the medium determined by multiplex immunoassay and ELISA (non-transformed data). $\mathrm{P}<0.05$ was considered significant. All statistical analyses were conducted in SPSS (v18, SPSS, Chicago, IL).

\section{Results}

\section{Effects of BSA and HSA on cytokine and adiponectin release from human adipose tissue}

In three experiments, subcutaneous adipose tissue was incubated for $2,4,6,8$, and $24 \mathrm{~h}$ in albumin-free medium or medium supplemented with 1\% HSA, 1\% BSA Fraction V, or $1 \%$ BSA Essentially Fatty Acid Free. Both preparations of BSA markedly induced the release of all nine cytokines as analyzed by multiplex immunoassay (Figure 1). Release of all nine cytokines over $24 \mathrm{~h}$ was higher in the two media containing BSA than in albumin-free medium or medium containing HSA $(\mathrm{p}<0.001)$. After $24 \mathrm{~h}$, the mean 


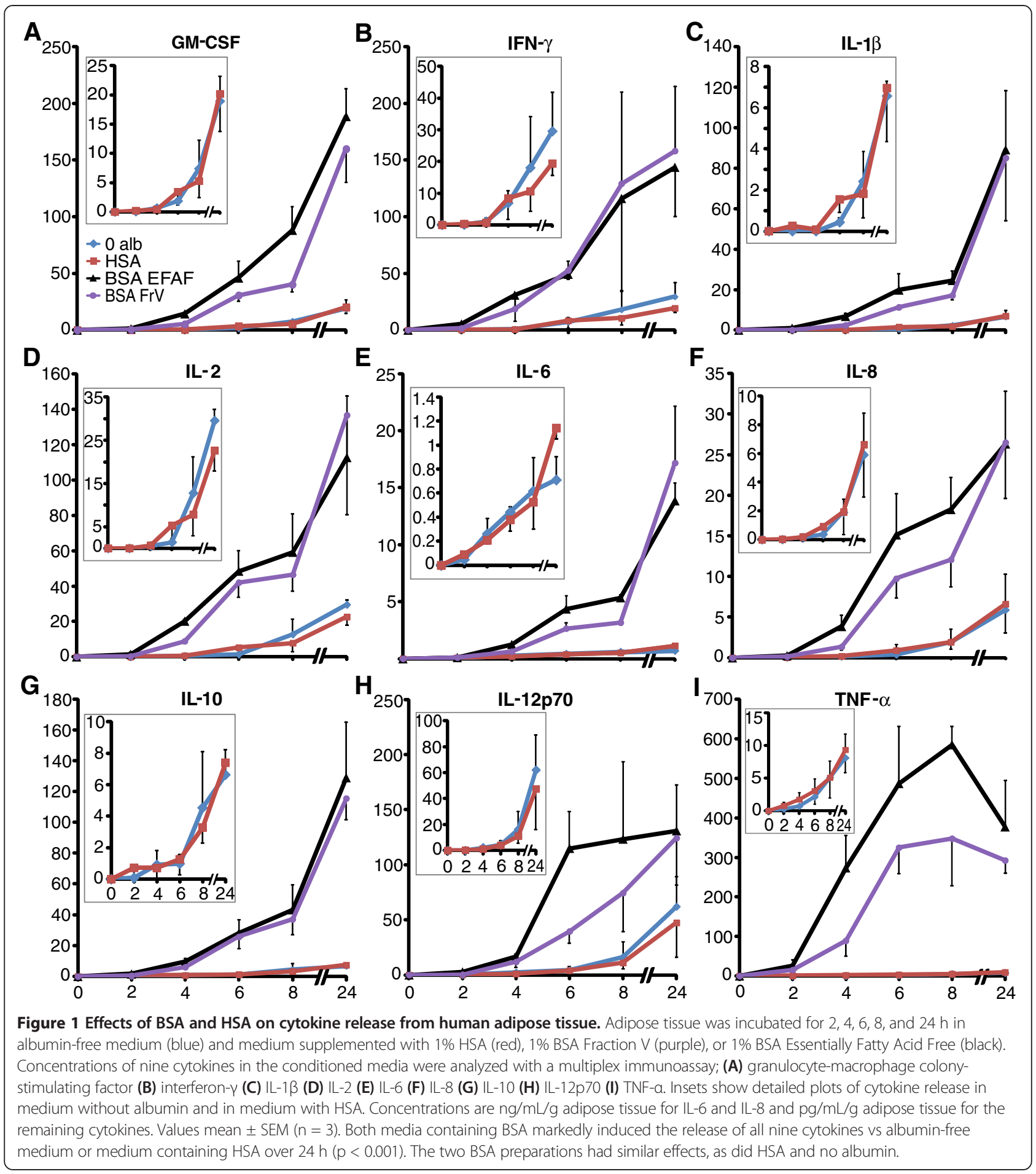

cytokine concentration was 6- to 47-fold higher in media containing BSA than in medium containing HSA. TNF$\alpha$ release at $24 \mathrm{~h}$ was 37 -fold greater after incubation with BSA Fraction V and 47-fold greater after incubation with BSA Essentially Fatty Acid Free than after incubation with HSA. Cytokine concentrations did not differ between the two media containing BSA (Figure 1) or between albumin-free medium and medium containing HSA (Figure 1, insets). The adiponectin concentration in the medium was not influenced by albumin supplementation, as analyzed by specific ELISA (data not shown).

Medium supplemented with $0.1 \%$ BSA Fraction V and 0.1\% BSA Essentially Fatty Acid Free also induced cytokine release. After $4 \mathrm{~h}$, concentrations of all cytokines, 
except IL-2 and IL-6, were higher in both media with $0.1 \%$ BSA than in albumin-free medium $(\mathrm{p}<0.05)$, as analyzed by multiplex immunoassay. After additional $20 \mathrm{~h}$ of incubation, concentrations of all nine cytokines were higher in both media with $0.1 \%$ BSA than in albuminfree medium $(\mathrm{p}<0.05$ IFN- $\gamma, \mathrm{p}<0.001$ all other cytokines) (data not shown).

\section{Endotoxin concentration in incubation media}

The endotoxin concentration in a batch of unconditioned medium without albumin was $<0.5$ and $1.6 \mathrm{pg} / \mathrm{mL}$ (duplicate). In three batches of unconditioned medium supplemented with 1\% HSA, the endotoxin concentration was 6.2, 9.1, and $3.8 \mathrm{pg} / \mathrm{mL}$, respectively. The corresponding concentrations of endotoxin in medium containing $1 \%$ BSA Fraction V and 1\% BSA Essentially Fatty Acid Free were 9200 and $11800 \mathrm{pg} / \mathrm{mL}$.

\section{Adipocyte size in subcutaneous and visceral human adipose tissue}

Adipocyte size in 11 paired biopsies of subcutaneous and visceral adipose tissue was analyzed with a computerized technique. The mean adipocyte volume was similar in subcutaneous and visceral adipose tissue (730 \pm 160 vs $665 \pm 217 \mathrm{pL}, \mathrm{p}=0.153)$. The mean diameter of reference microspheres was $97.63 \pm 0.25 \mu \mathrm{m}$ (range 97.21-97.90 $\mu \mathrm{m}, \mathrm{n}=11$ ). On average, 601 subcutaneous adipocytes (range 322-1245) and 515 visceral adipocytes (range 232-1164) were analyzed in each biopsy.

\section{Macrophage density in subcutaneous and visceral human} adipose tissue

The density of macrophages in 11 paired biopsies of subcutaneous and visceral adipose tissue was analyzed using immunohistochemistry. Macrophage density was higher in visceral than subcutaneous adipose tissue $(1.74 \pm 0.61$ vs $0.39 \pm 0.14$ macrophages $/ \mathrm{mm}^{2}, \mathrm{p}<0.05$ ) (Figure 2).

\section{Evaluation of the final short-term incubation protocol including HSA}

Subcutaneous adipose tissue from 10 subjects (five obese and five nonobese) was incubated for $2,4,6,8$, and $24 \mathrm{~h}$ in medium containing $1 \%$ HSA according to our final incubation protocol. Eleven paired biopsies of subcutaneous and visceral adipose tissue was also incubated accordingly. Adiponectin and omentin concentrations in the media were analyzed by ELISA. As expected, adiponectin was more abundantly released from adipose tissue of nonobese than of obese subjects $(\mathrm{p}<0.05)$ (Figure 3A), and adiponectin release from subcutaneous adipose tissue was inversely associated with subcutaneous adipocyte size at $4 \mathrm{~h}(\mathrm{r}=-0.85, \mathrm{p}<0.05, \mathrm{n}=7)$ and $24 \mathrm{~h}(\mathrm{r}=$ $-0.84, \mathrm{p}<0.05, \mathrm{n}=7$ ). As expected, omentin was almost exclusively released from the visceral depot $(p<0.001)$ (Figure 3B).

\section{Release of cytokines from subcutaneous and visceral adipose tissue}

Eleven paired biopsies of subcutaneous and visceral adipose tissue was incubated according to our final protocol. As shown by multiplex immunoassay, release of all nine cytokines but IL- 6 were more abundant from visceral than subcutaneous adipose tissue over $24 \mathrm{~h}$ of incubation (GMCSF $\mathrm{p}<0.001$, INF- $\gamma \mathrm{p}<0.001$, IL-1 $\beta \mathrm{p}<0.001$, IL-2 $\mathrm{p}<$ 0.01 , IL-6 $\mathrm{p}=0.062$, IL-8 $\mathrm{p}<0.001$, IL-10 $\mathrm{p}<0.01$, IL12 p70 p $<0.001$, TNF- $\alpha$ p $<0.001$ ) (data not shown).

\section{Release of adiponectin, chemerin, IL-6, and DPP4 from subcutaneous and visceral adipose tissue}

Paired biopsies of subcutaneous and visceral adipose tissue were incubated according to our final protocol, and



Figure 2 CD68 immunoreactivity of human adipose tissue. Positive signal appears red. Sections were counterstained with hematoxylin. Arrows indicate macrophages. Paired biopsies of (A) subcutaneous and (B) visceral adipose tissue (representative images). 

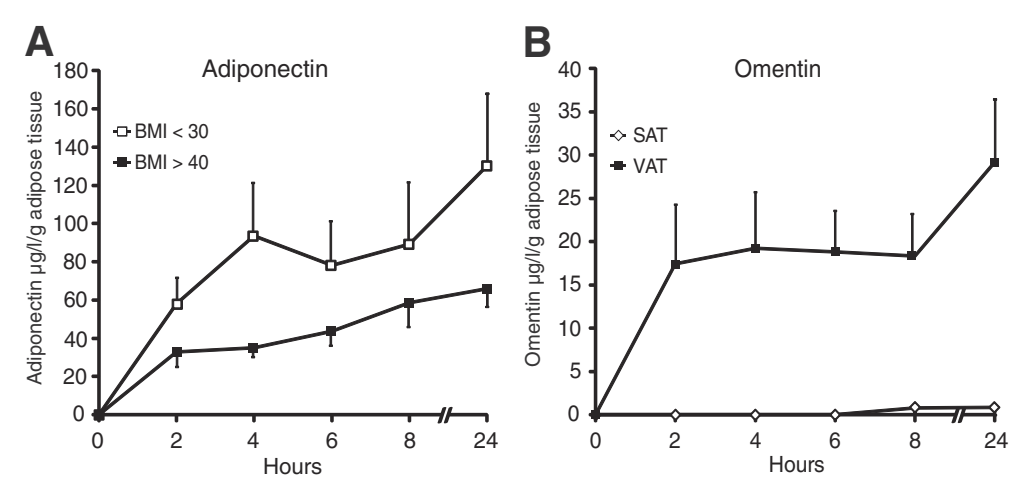

Figure 3 Release of adiponectin and omentin from human adipose tissue. Evaluation of the final incubation protocol including HSA. (A) Subcutaneous adipose tissue (SAT) from 10 subjects (5 obese and 5 nonobese) and (B) 11 paired biopsies of subcutaneous and visceral adipose tissue (VAT) were incubated for 2, 4, 6, 8, and $24 \mathrm{~h}$ in medium containing 1\% HSA according to our final incubation protocol. The media were analyzed for $(\mathbf{A})$ adiponectin and (B) omentin by ELISA. As expected, adiponectin was more abundantly released from adipose tissue of nonobese than obese subjects $(p<0.05)(\mathbf{A})$, and omentin was almost exclusively released from the visceral depot $(p<0.001)(\mathbf{B})$.

concentrations of adiponectin, chemerin, IL-6, and DPP4 were determined by ELISA. Adiponectin was more abundantly released from subcutaneous than visceral adipose tissue $(\mathrm{p}<0.01, \mathrm{n}=7$ ) (Figure 4A). IL-6 release from the depots was similar $(\mathrm{p}=0.315, \mathrm{n}=11)$ (Figure $4 \mathrm{~B})$, while chemerin and DPP4 were more abundantly released from visceral adipose tissue $(\mathrm{p}<0.05$ and $\mathrm{p}<0.001$, respectively, $\mathrm{n}=11$ ) (Figure $4 \mathrm{C}$ and $4 \mathrm{D}$ ). Adipokine release was linear for a maximum of $2-6 \mathrm{~h}$.

\section{Medium IL-6 concentrations determined by multiplex immunoassay and ELISA}

The IL-6 concentration in 148 samples of medium were analyzed by ELISA and multiplex immunoassay. Regression

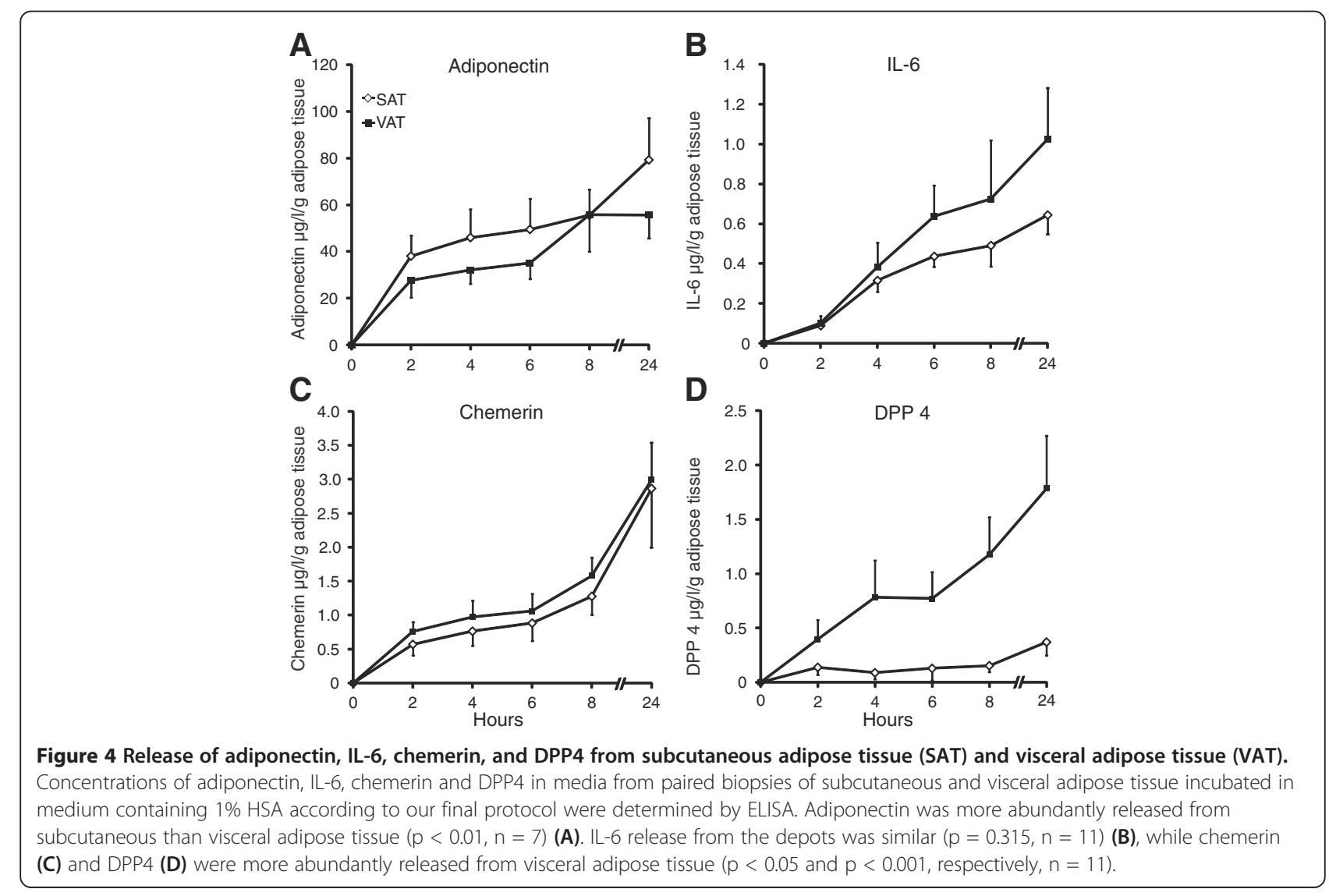


analysis revealed a linear relationship without intercept ( $y=0.714 x, R=0.987, p<0.001$ ), indicating almost complete agreement between the methods while the multiplex technique systematically underestimated the IL- 6 concentration in the samples by about $30 \%$.

\section{Discussion}

This study shows that adiponectin, chemerin, eight proinflammatory cytokines, and DPP4, all inflammatory and/or metabolic biomarkers, are released from human adipose tissue in a depot-dependent manner. Chemerin, cytokines, and DPP4 were more abundantly released from visceral than subcutaneous adipose tissue, while adiponectin release was higher from the subcutaneous depot. Our findings also showed that cytokine release from human adipose tissue was markedly induced by BSA but not by HSA which was therefore used in our final protocol.

In particular, when comparing adipose tissue biopsiesfrom different groups of subjects, from different depots, or from an individual at different time points-with respect to adipokine/cytokine release, in vitro conditions must be standardized and selected with care [18]. In tests of our system, we found that HSA added to the medium, in contrast to BSA, did not induce cytokine release from human adipose tissue [20]. Using our final incubation protocol to monitor adipokine release over $24 \mathrm{~h}$, we also obtained results consistent with previous well-established clinical findings [27-31]. First, adiponectin release was higher from abdominal biopsies of nonobese subjects than obese subjects [27,28,31]. Second, adiponectin release from subcutaneous adipose tissue was inversely associated with adipocyte size $[29,30]$. Further, omentin was released almost exclusively from visceral AT, consistent with reports that omentin mRNA is barely detectable in human subcutaneous adipose tissue or markedly lower in the subcutaneous than in the visceral depot [32,33]. Taken together, these findings suggest that our in vitro system is suitable for assessing the adipose tissue secretome and for investigating relative differences in adipokine/cytokine release from adipose tissue depots.

It may be noted that no differences in cytokine release was observed between medium containing HSA and medium without albumin. In a short-term incubation system like ours, with a high medium-to-adipose tissue ratio, supplementation of the medium with albumin may not be necessary.

As in a previous study of isolated adipocytes [20], cytokines were massively released when adipose tissue pieces were incubated in the presence of $0.1 \%$ or $1 \%$ BSA. Our results suggest that this effect of BSA may be mediated by a high concentration of endotoxin although immunomodulatory effects of albumin, not due to endotoxin contamination, also has been reported [34]. Depending on the cell/tissue type, endotoxin has a variety of effects mediated at the transcriptional and/or translational level. At low concentrations, the endotoxin lipopolysaccharide (LPS) reportedly increases the expression and release of cytokines from monocytes, monocyte-derived macrophages and in vitro differentiated adipocytes [35-37]. Levels of IL8 mRNA in human mononuclear cells, cultured for 10 days for differentiation, were increased after a 4-h exposure to LPS at a concentration of $1 \mathrm{pg} / \mathrm{mL}$ [35]. However, relatively slow IL-8 protein secretion from the same cells was reported only after stimulation with $10 \mathrm{ng} / \mathrm{mL}$ LPS, making it difficult to draw conclusion about the LPS dose required for an effect on IL-8 release in this type of macrophage [35]. In our study, the endotoxin level was about $1 \mathrm{pg} / \mathrm{mL}$ in albumin-free medium and 3-10 pg/mL in incubation medium containing 1\% HSA. Analysis of our conditioned media over $24 \mathrm{~h}$ revealed no differences in cytokine concentrations between media with or without HSA, despite the somewhat higher endotoxin level in medium containing HSA. This finding strongly suggests an absent or negligible effect of endotoxin, or other potential immunomodulatory feature of albumin, in our incubation system.

As mentioned above, measures of obesity are associated with reduced plasma levels of adiponectin, an adipokine predominantly produced by adipocytes $[27,28,31,38]$. Accumulation of visceral and truncal fat, in particular, may be linked to hypoadiponectinemia [28,39]. However, in vitro studies of adiponectin release from human subcutaneous and visceral adipose tissue have yielded inconsistent results. Adiponectin release from the depots was similar after incubation of tissue pieces for a couple of hours or for two days $[40,41]$, while secretion of adiponectin was $28 \%$ higher from omental than subcutaneous adipocytes in primary culture, although the difference did not reach statistical significance [42]. In primary cultures of adipocytes from women with visceral obesity, adiponectin release was lower in omental than subcutaneous adipocytes [43]. Considerable methodological differences may underlie these discrepancies. Consistent with our findings, gene expression studies showed lower adiponectin mRNA levels in visceral than in subcutaneous adipose tissue in both lean and obese subjects $[44,45]$.

To our knowledge, the possibility that release of chemerin is depot-dependent has not been investigated by incubation of human adipose tissue. Chemerin is a rather novel adipokine that regulates adipogenesis and may induce insulin resistance $[46,47]$. In obese subjects, elevated circulating levels correlate with BMI and measures of central adiposity, such as waist-hip ratio, waist circumference, and visceral adipose tissue mass [48]. Further, expression of chemerin mRNA in adipose tissue of patients with type 2 diabetes was more pronounced in the omentum than in the subcutaneous depot, suggesting 
a fat depot-dependent regulation of chemerin expression [49]. In the present study, the higher chemerin release from the visceral than the subcutaneous depot was marginal but still significant over $24 \mathrm{~h}$.

DPP4, another recently discovered adipokine, may also impair insulin sensitivity [50]. Serum DPP4 is increased in obesity and reduced after weight loss and is a potential biomarker of metabolic syndrome [50]. In contrast, expression of DPP4 mRNA in subcutaneous adipose tissue was higher in lean women than in age-matched obese women [51]. In the present study, the first to investigate potential depot-dependent release of DPP4 from adipose tissue, visceral adipose tissue was by far the major site. This finding is consistent with a western blot analysis that showed higher DPP4 levels in visceral than in subcutaneous adipose tissue in obese subjects, and a similar trend also in lean subjects [50].

Accumulating evidence suggests that obesity-in particular central/visceral accumulation of fat-and its comorbidities correlate with increases in circulating levels of inflammatory proteins such as C-reactive protein and IL-6 [4,5,52,53]. Plasma IL-6 concentrations were also reported to be higher in portal vein than in peripheral artery blood in obese subjects suggesting that visceral fat is an important source of IL-6 in obese people [54]. In vitro studies comparing release of proinflammatory cytokines such as IL-1 $\beta$, IL-6, IL-8, and IL-18 from subcutaneous and visceral adipose tissue, usually in presence of BSA or fetal calf serum $[13,15,53,55]$ but also in serum/ albumin-free medium [13], generally show that the visceral depot is by far the dominant site $[13,15,55,56]$, consistent with our findings. However, for TNF- $\alpha$, similar release in the depots was previously reported [56,57]. Further, nonfat cells of the tissue are thought to be responsible for the major part of cytokine release $[13,15,55]$, in line with our observation of higher macrophage density in the visceral depot. A larger number of observations would probably be required to demonstrate a significant association between macrophage density and cytokine release although we observed positive relationships (not shown). We found that release of IL-6, unlike the other cytokines we studied, was similar in the subcutaneous and visceral depots, although it tended to be higher in visceral adipose tissue. The reason for this is not clear but in light of previous clinical observations, and the fact that all other investigated cytokines in the present study were more abundantly released from the visceral depot, it is reasonable to assume that the non-significant difference between the depots regarding IL-6 release is due to the relatively small number of observations which limited our power.

Another possible limitation of this study is the rather heterogeneous group of patients included. However, analysis of paired biopsies from the obese subjects separately did not affect the results obtained. Further, the multiplex immunoassay is mainly intended for screening purposes. However, we observed an almost complete agreement between the multiplex immunoassay and the specific ELISA regarding analysis of IL-6 although the multiplex technique systematically underestimated the IL6 concentration by about one third.

\section{Conclusions}

Taken together, our findings show that human adipose tissue is characterized by depot-dependent release of many adipokines. Chemerin, GM-CSF, IFN- $\gamma$, IL- $1 \beta$, IL2, IL-8, IL-10, IL-12p70, TNF- $\alpha$, and DPP4 were more abundantly released from visceral than subcutaneous adipose tissue, while adiponectin release was higher from the subcutaneous depot. These results highlight functional differences between visceral and subcutaneous adipose tissue, and a mechanistic link between regional fat accumulation and metabolic disorders. Our results also demonstrate that the system applied, including HSA instead of BSA, is suitable for further investigations of the human adipose tissue secretome and relative differences between depots. Further, for any in vitro system for human adipose tissue or adipocytes, potential albumin effects on tissue/cell function should be considered.

\section{Competing interests}

The authors declare that they have no competing interests.

\section{Authors' contributions}

SE and ML designed the study. HS and BO collected patient material and performed the experiments. HS, SE and ML analyzed and interpreted the data. HS, BO, SE drafted the manuscript. ML revised the final version of the manuscript. All authors read and approved the final manuscript.

\section{Acknowledgments}

We thank Kjell Pettersson, University of Gothenburg, and Anders Odén, Chalmers University of Technology, for statistical consultation, professor Eva Jennische, Institute of Biomedicine, University of Gothenburg, for advice regarding analysis of macrophage density, Department of Clinical Chemistry, Sahlgrenska University Hospital, for advice regarding immunoassays, and Stephen Ordway, Golden Gate Biomedical Communications, San Francisco, CA, for editorial assistance. This study was funded by the Swedish Research Council (K2007-54X-20325-01-3), the Swedish Diabetes Association Research Foundation (DIA2010-086, DIA2011-090), the Swedish government under the LUA/ALF agreement (ALFGBG-11447, ALFGBG-144781), the Wilhelm and Martina Lundgren Foundation, and the Lisa and Johan Grönberg Foundation.

\section{Author details}

'Department of Clinical Chemistry and Transfusion Medicine, Institute of Biomedicine, Sahlgrenska Academy, University of Gothenburg, S-405 30 Gothenburg, Sweden. ${ }^{2}$ Department of Internal Medicine, Institute of Medicine, Sahlgrenska Academy, University of Gothenburg, S-405 30 Gothenburg, Sweden. ${ }^{3}$ Department of Clinical Chemistry, Sahlgrenska University Hospital, Bruna stråket 16, S-413 45 Gothenburg, Sweden.

Received: 19 July 2013 Accepted: 16 January 2014 Published: 22 January 2014

\section{References}

1. Kershaw EE, Flier JS: Adipose tissue as an endocrine organ. $J$ Clin Endocrinol Metab 2004, 89(6):2548-2556.

2. Ahima RS, Osei SY: Adipokines in obesity. Front Horm Res 2008, 36:182-197. 
3. Deng Y, Scherer PE: Adipokines as novel biomarkers and regulators of the metabolic syndrome. Ann N Y Acad Sci 2010, 1212:E1-E19.

4. Ouchi N, Parker JL, Lugus JJ, Walsh K: Adipokines in inflammation and metabolic disease. Nat Rev Immunol 2011, 11(2):85-97.

5. Hotamisligil GS: Inflammation and metabolic disorders. Nature 2006, 444(7121):860-867.

6. Preis SR, Massaro JM, Robins SJ, Hoffmann U, Vasan RS, Irlbeck T, Meigs JB, Sutherland P, D'Agostino RB Sr, O'Donnell CJ, et al: Abdominal subcutaneous and visceral adipose tissue and insulin resistance in the Framingham heart study. Obesity (Silver Spring) 2010, 18(11):2191-2198.

7. Sam S, Haffner S, Davidson MH, D'Agostino RB Sr, Feinstein S, Kondos $G$, Perez A, Mazzone T: Relationship of abdominal visceral and subcutaneous adipose tissue with lipoprotein particle number and size in type 2 diabetes. Diabetes 2008, 57(8):2022-2027.

8. Jernas M, Palming J, Sjoholm K, Jennische E, Svensson PA, Gabrielsson BG, Levin M, Sjogren A, Rudemo M, Lystig TC, et al: Separation of human adipocytes by size: hypertrophic fat cells display distinct gene expression. FASEB J 2006, 20(9):1540-1542.

9. Anderson EK, Gutierrez DA, Hasty AH: Adipose tissue recruitment of leukocytes. Curr Opin Lipidol 2010, 21(3):172-177.

10. Alvehus M, Buren J, Sjostrom M, Goedecke J, Olsson T: The human visceral fat depot has a unique inflammatory profile. Obesity (Silver Spring) 2010, 18(5):879-883.

11. Gabrielsson BG, Johansson JM, Lonn M, Jernas M, Olbers T, Peltonen M, Larsson I, Lonn L, Sjostrom L, Carlsson B, et al: High expression of complement components in omental adipose tissue in obese men. Obes Res 2003, 11(6):699-708.

12. Samaras K, Botelho NK, Chisholm DJ, Lord RV: Subcutaneous and visceral adipose tissue gene expression of serum adipokines that predict type 2 diabetes. Obesity (Silver Spring) 2010, 18(5):884-889.

13. Fried SK, Bunkin DA, Greenberg AS: Omental and subcutaneous adipose tissues of obese subjects release interleukin-6: depot difference and regulation by glucocorticoid. J Clin Endocrinol Metab 1998, 83(3):847-850.

14. Van Harmelen V, Reynisdottir S, Eriksson P, Thorne A, Hoffstedt J, Lonnqvist $F$, Arner P: Leptin secretion from subcutaneous and visceral adipose tissue in women. Diabetes 1998, 47(6):913-917.

15. Fain JN, Madan AK, Hiler ML, Cheema P, Bahouth SW: Comparison of the release of adipokines by adipose tissue, adipose tissue matrix, and adipocytes from visceral and subcutaneous abdominal adipose tissues of obese humans. Endocrinology 2004, 145(5):2273-2282.

16. Sopasakis VR, Sandqvist M, Gustafson B, Hammarstedt A, Schmelz M, Yang $X$, Jansson PA, Smith U: High local concentrations and effects on differentiation implicate interleukin- 6 as a paracrine regulator. Obes Res 2004, 12(3):454-460.

17. Madani R, Karastergiou K, Ogston NC, Miheisi N, Bhome R, Haloob N, Tan GD, Karpe F, Malone-Lee J, Hashemi M, et al: RANTES release by human adipose tissue in vivo and evidence for depot-specific differences. Am J Physiol Endocrinol Metab 2009, 296(6):E1262-E1268.

18. Carswell KA, Lee MJ, Fried SK: Culture of isolated human adipocytes and isolated adipose tissue. Methods Mol Biol 2012, 806:203-214.

19. Arner P: Techniques for the measurement of white adipose tissue metabolism: a practical guide. Int J Obes Relat Metab Disord 1995, 19(7):435-442.

20. Schlesinger JB, van Harmelen V, Alberti-Huber CE, Hauner H: Albumin inhibits adipogenesis and stimulates cytokine release from human adipocytes. Am J Physiol Cell Physiol 2006, 291(1):C27-C33.

21. Ottosson M, Vikman-Adolfsson K, Enerback S, Elander A, Bjorntorp P, Eden S: Growth hormone inhibits lipoprotein lipase activity in human adipose tissue. J Clin Endocrinol Metab 1995, 80(3):936-941.

22. Ottosson M, Lonnroth P, Bjorntorp P, Eden S: Effects of cortisol and growth hormone on lipolysis in human adipose tissue. J Clin Endocrinol Metab 2000, 85(2):799-803.

23. Smith U, Sjostrom L, Bjornstorp P: Comparison of two methods for determining human adipose cell size. J Lipid Res 1972, 13(6):822-824

24. Bjornheden T, Jakubowicz B, Levin M, Oden B, Eden S, Sjostrom L, Lonn M: Computerized determination of adipocyte size. Obes Res 2004, 12(1):95-105.

25. Goldrick RB: Morphological changes in the adipocyte during fat deposition and mobilization. Am J Physiol 1967, 212(4):777-782.

26. Kuehl RO: Design of experiments: statistical principles of research design and analysis. 2nd edition. Pacific Grove: Duxbury-Thomson Learning; 2000.
27. Arita Y, Kihara S, Ouchi N, Takahashi M, Maeda K, Miyagawa J, Hotta K, Shimomura I, Nakamura T, Miyaoka K, et al: Paradoxical decrease of an adipose-specific protein, adiponectin, in obesity. Biochem Biophys Res Commun 1999, 257(1):79-83.

28. Turer AT, Khera A, Ayers CR, Turer CB, Grundy SM, Vega GL, Scherer PE: Adipose tissue mass and location affect circulating adiponectin levels. Diabetologia 2011, 54(10):2515-2524.

29. Bahceci M, Gokalp D, Bahceci S, Tuzcu A, Atmaca S, Arikan S: The correlation between adiposity and adiponectin, tumor necrosis factor alpha, interleukin- 6 and high sensitivity C-reactive protein levels. Is adipocyte size associated with inflammation in adults? J Endocrinol Invest 2007, 30(3):210-214.

30. Hammarstedt A, Graham TE, Kahn BB: Adipose tissue dysregulation and reduced insulin sensitivity in non-obese individuals with enlarged abdominal adipose cells. Diabetology \& Metabolic Syndrome 2012, 4(1):42.

31. Murdolo G, Hammarstedt A, Schmelz M, Jansson PA, Smith U: Acute hyperinsulinemia differentially regulates interstitial and circulating adiponectin oligomeric pattern in lean and insulin-resistant, obese individuals. J Clin Endocrinol Metab 2009, 94(11):4508-4516.

32. Yang RZ, Lee MJ, Hu H, Pray J, Wu HB, Hansen BC, Shuldiner AR, Fried SK, McLenithan JC, Gong DW: Identification of omentin as a novel depotspecific adipokine in human adipose tissue: possible role in modulating insulin action. Am J Physiol Endocrinol Metab 2006, 290(6):E1253-E1261.

33. Auguet T, Quintero Y, Riesco D, Morancho B, Terra X, Crescenti A, Broch M, Aguilar C, Olona M, Porras JA, et al: New adipokines vaspin and omentin. Circulating levels and gene expression in adipose tissue from morbidly obese women. BMC Med Gen 2011, 12:60.

34. Wheeler DS, Giuliano JS Jr, Lahni PM, Denenberg A, Wong HR, Zingarelli B: The immunomodulatory effects of albumin in vitro and in vivo. Adv Phar Sc 2011, 2011:691928.

35. Zhong WW, Burke PA, Hand AT, Walsh MJ, Hughes LA, Forse RA: Regulation of cytokine mRNA expression in lipopolysaccharide-stimulated human macrophages. Arch Surg 1993, 128(2):158-163. discussion 163-154.

36. Hoch M, Eberle AN, Peterli R, Peters T, Seboek D, Keller U, Muller B, Linscheid P: LPS induces interleukin-6 and interleukin-8 but not tumor necrosis factor-alpha in human adipocytes. Cytokine 2008, 41(1):29-37.

37. Arbabi S, Garcia I, Bauer GJ, Maier RV: Alcohol (ethanol) inhibits IL-8 and TNF: role of the p38 pathway. J Immunol 1999, 162(12):7441-7445.

38. Turer AT, Scherer PE: Adiponectin: mechanistic insights and clinical implications. Diabetologia 2012, 55(9):2319-2326.

39. Kishida K, Kim KK, Funahashi T, Matsuzawa Y, Kang HC, Shimomura I: Relationships between circulating adiponectin levels and fat distribution in obese subjects. J Atheroscler Thromb 2011, 18(7):592-595.

40. Kovacova Z, Tencerova M, Roussel B, Wedellova Z, Rossmeislova L, Langin D, Polak J, Stich V: The impact of obesity on secretion of adiponectin multimeric isoforms differs in visceral and subcutaneous adipose tissue. Int J Obes (Lond) 2012, 36(10):1360-1365.

41. Phillips SA, Ciaraldi TP, Oh DK, Savu MK, Henry RR: Adiponectin secretion and response to pioglitazone is depot dependent in cultured human adipose tissue. Am J Physiol Endocrinol Metab 2008, 295(4):E842-E850.

42. Motoshima H, Wu X, Sinha MK, Hardy VE, Rosato EL, Barbot DJ, Rosato FE, Goldstein BJ: Differential regulation of adiponectin secretion from cultured human omental and subcutaneous adipocytes: effects of insulin and rosiglitazone. J Clin Endocrinol Metab 2002, 87(12):5662-5667.

43. Drolet R, Belanger C, Fortier M, Huot C, Mailloux J, Legare D, Tchernof A: Fat depot-specific impact of visceral obesity on adipocyte adiponectin release in women. Obesity (Silver Spring) 2009, 17(3):424-430.

44. Lihn AS, Bruun JM, He G, Pedersen SB, Jensen PF, Richelsen B: Lower expression of adiponectin mRNA in visceral adipose tissue in lean and obese subjects. Mol Cell Endocrinol 2004, 219(1-2):9-15.

45. Hernandez-Morante JJ, Milagro Fl, Larque E, Lujan J, Martinez JA, Zamora S, Garaulet M: Relationship among adiponectin, adiponectin gene expression and fatty acids composition in morbidly obese patients. Obes Surg 2007, 17(4):516-524.

46. Sell H, Laurencikiene J, Taube A, Eckardt K, Cramer A, Horrighs A, Arner P, Eckel $\mathrm{J}$ : Chemerin is a novel adipocyte-derived factor inducing insulin resistance in primary human skeletal muscle cells. Diabetes 2009, 58(12):2731-2740.

47. Goralski KB, McCarthy TC, Hanniman EA, Zabel BA, Butcher EC, Parlee SD, Muruganandan S, Sinal CJ: Chemerin, a novel adipokine that regulates adipogenesis and adipocyte metabolism. J Biol Chem 2007, 282(38):28175-28188. 
48. Rourke JL, Dranse HJ, Sinal CJ: Towards an integrative approach to understanding the role of chemerin in human health and disease. Obes Rev 2012, 2012:2012.

49. Chakaroun R, Raschpichler M, Kloting N, Oberbach A, Flehmig G, Kern M, Schon MR, Shang E, Lohmann T, Dressler M, et al: Effects of weight loss and exercise on chemerin serum concentrations and adipose tissue expression in human obesity. Metabolism 2012, 61(5):706-714.

50. Lamers D, Famulla S, Wronkowitz N, Hartwig S, Lehr S, Ouwens DM, Eckardt K, Kaufman JM, Ryden M, Muller S, et al: Dipeptidyl peptidase 4 is a novel adipokine potentially linking obesity to the metabolic syndrome. Diabetes 2011, 60(7):1917-1925.

51. Kos K, Baker AR, Jernas M, Harte AL, Clapham JC, O'Hare JP, Carlsson L, Kumar S, McTernan PG: DPP-IV inhibition enhances the antilipolytic action of NPY in human adipose tissue. Diabetes Obes Metab 2009, 11(4):285-292.

52. Lapice E, Maione S, Patti L, Cipriano P, Rivellese AA, Riccardi G, Vaccaro O: Abdominal adiposity is associated with elevated C-reactive protein independent of BMI in healthy nonobese people. Diabetes Care 2009, 32(9):1734-1736

53. Cartier A, Lemieux I, Almeras N, Tremblay A, Bergeron J, Despres JP: Visceral obesity and plasma glucose-insulin homeostasis: contributions of interleukin-6 and tumor necrosis factor-alpha in men. J Clin Endocrinol Metab 2008, 93(5):1931-1938

54. Fontana L, Eagon JC, Trujillo ME, Scherer PE, Klein S: Visceral fat adipokine secretion is associated with systemic inflammation in obese humans. Diabetes 2007, 56(4):1010-1013.

55. Bruun JM, Lihn AS, Madan AK, Pedersen SB, Schiott KM, Fain JN, Richelsen B: Higher production of IL-8 in visceral vs. subcutaneous adipose tissue. Implication of nonadipose cells in adipose tissue. Am J Physiol Endocrinol Metab 2004, 286(1):E8-E13.

56. Koenen $T B$, Stienstra $R$, van Tits $L$, Joosten $L A$, van Velzen JF, Hijmans A, Pol JA, van der Vliet JA, Netea MG, Tack CJ, et al: The inflammasome and caspase-1 activation: a new mechanism underlying increased inflammatory activity in human visceral adipose tissue. Endocrinology 2011, 152(10):3769-3778.

57. Eriksson P, Van Harmelen V, Hoffstedt J, Lundquist P, Vidal H, Stemme V, Hamsten A, Arner P, Reynisdottir S: Regional variation in plasminogen activator inhibitor-1 expression in adipose tissue from obese individuals. Thromb Haemostasis 2000, 83(4):545-548.

doi:10.1186/1472-6823-14-7

Cite this article as: Svensson et al: Adiponectin, chemerin, cytokines, and dipeptidyl peptidase 4 are released from human adipose tissue in a depot-dependent manner: an in vitro system including human serum albumin. BMC Endocrine Disorders 2014 14:7.

\section{Submit your next manuscript to BioMed Central and take full advantage of:}

- Convenient online submission

- Thorough peer review

- No space constraints or color figure charges

- Immediate publication on acceptance

- Inclusion in PubMed, CAS, Scopus and Google Scholar

- Research which is freely available for redistribution 